\title{
ESTUDO FITOQUÍMICO E ANÁLISE DE FOTOPROTEÇÃO DOS EXTRATOS E ÓLEOS ESSENCIAIS DE Aniba canelilla (H.B.K) MEZ
}

\section{PHYTOCHEMICAL STUDY AND PHOTOPROTECTION ANALYSIS OF EXTRACTS AND ESSENTIAL OILS OF Aniba canelilla (H.B.K) MEZ}

\author{
A. V. FARIAS ${ }^{1}$, F. S. FERNANDES ${ }^{2}$, R. A. dos SANTOS $^{3}$ E. S. de SOUZA $^{1}$ e J. V. B. de \\ SOUZA $^{2}$ \\ ${ }^{1}$ Universidade do Estado do Amazonas, Escola Superior de Tecnologia, Departamento de \\ Engenharia Química \\ ${ }^{2}$ Instituto Nacional de Pesquisas da Amazônia, Laboratório de Micologia \\ ${ }^{3}$ Universidade do Estado do Amazonas, Escola Superior de Ciências da Saúde, Programa de \\ Pós-graduação em Biotecnologia e Recursos Naturais da Amazônia \\ E-mail: amanda_vffarias@hotmail.com
}

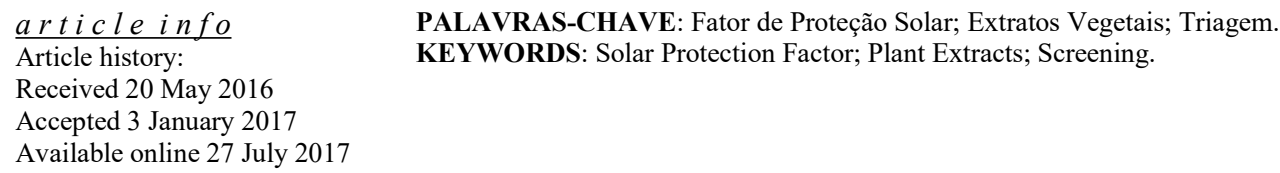

RESUMO: A Aniba canelilla (H.B.K.) Mez é uma espécie da região Amazônica, popularmente conhecida como pau-precioso, que produz metabólitos secundários com estruturas químicas semelhantes às dos filtros solares sintéticos. Dessa forma, o objetivo deste trabalho foi determinar o perfil fitoquímico dos extratos e óleos de Aniba canelilla e avaliar atividade fotoprotetora dos mesmos. Os óleos essenciais foram obtidos por hidrodestilação por arraste a vapor e os extratos etanólicos foram submetidos a uma partição líquido-líquido, com n-hexano e diclorometano, resultando também uma fase hidroalcoólica. Em seguida realizou-se uma triagem fitoquímica e depois calculou-se o FPS. Adiante disso, a fase diclorometano dos galhos de A. canelilla apresentou um fator de proteção de 122,60, valor alto comparado com os padrões na mesma concentração $(0,1 \%)$, sendo assim será realizado um estudo mais detalhado em relação a sua composição química para que seus constituintes possam ser isolados e identificados para posteriormente serem empregados em formulações de filtro solar.

\begin{abstract}
Aniba canelilla (H.B.K.) Mez is a species of the Amazon region, popularly known as precious wood, which produces secondary metabolites with chemical structures similar to synthetic sunscreens. Thus, the objective of this work was to determine the phytochemical profile of the extracts and oils of Aniba canelilla and to evaluate the photoprotective activity of the extracts and oils of Aniba canelilla. The essential oils were obtained by steam distillation and the ethanolic extracts were submitted to a liquid-liquid partition, with $n$ hexane and dichloromethane, also resulting in a hydroalcoholic phase. Phytochemical screenings were then performed and FPS was then calculated. In addition, the dichloromethane phase of the A. canelilla branches presented a protection factor of 122.60, a high value compared to the standards at the same concentration $(0.1 \%)$, thus a more detailed study will be carried out in relation to their Chemical composition so that its constituents can be isolated and identified for later use in sunscreen formulations.
\end{abstract}




\section{INTRODUÇÃO}

As radiações ultravioletas que apreendem a superfície terrestre proporcionam além de bem estar ao homem, o surgimento de cânceres cutâneos na pele humana, podendo assim provocar danos ao DNA e ocasionar alterações químicas e histológicas na epiderme. Por isso, uma profilaxia contra essa radiação é o uso de filtros solares que reduzem a quantidade de radiação absorvida pela pele, servindo como uma barreira fotoprotetora (Araújo et al., 2008).

Atualmente, muitos extratos e óleos essenciais de plantas têm sido empregados em preparações cosméticas como loções hidroalcoólicas e emulsões fotoprotetoras, pois as mesmas exibem moléculas ou complexos moleculares capazes de absorver e refletir a radiação ultravioleta, substâncias semelhantes aos filtros sintéticos.

Um fotoprotetor é considerado adequado na proteção à radiação UVA quando o mesmo expõe um valor de comprimento de onda crítico $(\lambda \mathrm{C})$ superior ou igual a $370 \mathrm{~nm}$. A proteção em relação à radiação UVA é superior, quanto maior o valor do comprimento de onda crítico. Contudo, ele não leva em análise a intensidade de todo o espectro, permitindo que um filtro com proteção inferior possa apresentar o mesmo valor de $\lambda \mathrm{C}$ que outro, com proteção máxima (Boots The Chemists, 2004).

Conforme descrito por Bobin et al. (1994), o espectro de absorção dos flavonoides quando dispersos em etanol e metanol mostra-se com dois picos, sendo um presente entre 240 a $280 \mathrm{~nm}$ e o outro nos comprimentos de 300 a $500 \mathrm{~nm}$. Segundo Santana et al. (2001), a presença de taninos na planta identifica um potencial na absorção da radiação UV. Portanto, realizou-se uma triagem fitoquímica para avaliar a presença dos mesmos no extratos e óleos de $A$. canelilla.

A Aniba canelilla é uma planta que oferece uma madeira de ótima qualidade e da qual é extraído o óleo essencial de interesse, cujo componente majoritário é o 1-nitro-2-feniletano, responsável pelo odor semelhante ao da canela. Algumas atividades como vasorelaxante e cardiovascular (Interaminense et al., 2013) tornam-se importantes quanto ao estudo em relação à planta. Propõe-se então, neste trabalho, determinar a capacidade fotoprotetora dos extratos etanólicos e do óleo essencial da espécie Aniba e determinar por meio de uma triagem fitoquímica, metabólitos que possivelmente sejam responsáveis por essa fotoproteção.

\section{METODOLOGIA}

\subsection{Coleta do Material Vegetal}

Folhas e galhos de $A$. canelilla foram coletados no período chuvoso (abril de 2011) e no período seco (setembro de 2014) na Reserva Florestal Adolpho Ducke em Manaus, Amazonas, no período matutino. O material vegetal foi colhido de dez árvores de $A$. canelilla e utilizado tanto para a obtenção do óleo essencial quanto para obtenção dos extratos etanólicos. 


\subsection{Obtenção dos Extratos Etanólicos de Folhas e Galhos de Aniba canelilla}

O material vegetal foi seco em temperatura ambiente em local arejado durante 10 dias, e após esse período foi triturado em moinho elétrico de facas com tela de $3 \mathrm{~mm}$. O material foi macerado à frio em álcool etílico 92,8 $8^{\circ}$ INPM à temperatura ambiente por 3 ciclos de 72 horas com filtração e renovação do solvente a cada ciclo (Silva, 2012). O filtrado foi submetido à evaporação sob pressão reduzida, à $40^{\circ} \mathrm{C}$, em evaporador rotativo. $\mathrm{O}$ extrato bruto resultante foi dissolvido em etanol-água (1:3) e submetido à partição líquido-líquido, utilizando n-hexano e diclorometano, restando ainda uma fração hidroalcoólica que foi liofilizada.

\subsection{Obtenção dos Óleos Essenciais}

Os óleos essenciais de folhas e galhos de A. canelilla foram obtidos por arraste a vapor em aparelho tipo Clevenger modificado, onde 100 gramas do material vegetal foram destilados com 1000 gramas de água destilada a temperatura de $100{ }^{\circ} \mathrm{C}$ durante três horas e trinta minutos para folhas e seis horas para galhos (Chaar, 2000).

\subsection{Análise Fitoquímica Qualitativa Preliminar}

Foi realizada uma avaliação fitoquímica (testes para alcaloides, flavonoides e taninos) através de um processo de prospecção qualitativa (Matos, 1997).

\subsection{Determinação do Fator de Proteção Solar (FPS)}

O FPS foi obtido pelo método espectrofotométrico desenvolvido por Mansur et al. (1986), onde foram preparadas soluções dos óleos essenciais, extratos etanólicos e fases diclorometânicas, hexânicas e hidroalcoólicas de $A$. canelilla na concentração de $1 \%(\mathrm{~m} / \mathrm{m})$ seguidas de diluições para análise; resultando numa concentração de $0,1 \%$.

As soluções de óleos e extratos foram preparadas com isopropanol e etanol, respectivamente, e assim, realizou-se uma varredura entre os comprimentos de onda de 280 a 400nm (Espectrofotômetro Shimadzu, modelo UV-1800) em cubeta de quartzo de 1,0 cm de caminho óptico. As absorbâncias obtidas foram utilizadas para o cálculo do FPS in vitro e também necessárias para a elaboração dos espectros de absorção, utilizando a Equação 1. Além disso, determinou-se a razão UVA/UVB a fim de conhecer sua proteção em relação à radiação UVA, proposta por Boots the Chemist (2004). Quercetina, benzofenona, ácido paminobenzóico, metoxinamato de octila e um protetor comercial foram utilizados como padrões.

$$
F P S=F C x \sum_{290}^{320} E E(\lambda) x I(\lambda) x A b s(\lambda)
$$


Sendo: FC o fator de correção; $\operatorname{EE}(\lambda)$ o efeito eritemogênico da radiação de comprimento de onda $\lambda ; \mathrm{I}(\lambda)$ a intensidade do sol no comprimento de onda $\lambda ; \operatorname{Abs}(\lambda)$ a absorbância da solução no comprimento de onda $\lambda$.

\section{RESULTADOS E DISCUSSÃO}

\subsection{Triagem Fitoquímica dos Metabólitos de Aniba canelilla}

$\mathrm{Na}$ avaliação para alcaloides, os resultados foram considerados positivos pela formação de um precipitado ou turvação da solução. Os testes para taninos foram considerados positivos pela formação de uma coloração verde ou azulada e ainda pelo desenvolvimento de um precipitado. Para flavonoides, os testes positivos foram assim considerados, quando a solução observada em comparação com o extrato bruto, exibiu uma coloração que variou entre um róseo e vermelho intenso. Os resultados dos ensaios fitoquímicos dos extratos, fases e óleos essenciais das folhas e galhos de A. canelilla foram positivos para essas classes de metabólitos. Contudo, os extratos e fases do período seco, em comparação com o período chuvoso, não foram positivos para flavonoides, ocasionando assim uma redução na absorção do mesmo, pois, segundo Bobin et al. (1994), o teor de flavonoides e taninos sintetizados por uma planta é considerado fator importante de proteção para as plantas contra a radiação ultravioleta.

Tabela 2 - Rendimento e concentração dos extratos pesquisados.

\begin{tabular}{lcc}
\hline Extrato & Rendimento $(\%)$ & Concentração $(\mathrm{mg} / \mathrm{ml})$ \\
\hline Guaraná & 12,25 & 122,5 \\
Amor Crescido & 7,3 & 0,73 \\
Murumuru & 6,406 & 64,1 \\
Copaíba & 6,194 & 61,9 \\
Buriti & 5,95 & 59,5 \\
Cupuaçu & 5,466 & 54,66 \\
Crajiru & 4,382 & 43,8 \\
Andiroba & 4,206 & 42,06 \\
Noni & 2,048 & 20,5 \\
Açaí & 1 & 10 \\
Castanha do Pará & 0,65 & 6,5 \\
Mulateiro & 0,15 & 1,5 \\
\hline
\end{tabular}

\subsection{Análise do Fator de Proteção Solar}

Os resultados da atividade fotoprotetora do material vegetal coletado no período seco foram comparados com os dados referentes ao período chuvoso. O valor máximo de FPS foi obtido para a fase diclorometano dos galhos. Observa-se que extratos exibiram uma alta absorção da radiação UVB em comparação com os padrões. De acordo com a triagem fitoquímica, os extratos de folhas e galhos de $A$. canelilla apresentaram no período chuvoso 
taninos e flavonoides, o que justifica a grande absorção da radiação nesse período. Segundo a revista Boots The Chemists (2004), os óleos das folhas e galhos coletados nos dois períodos apresentaram uma boa proteção na região do UVA, enquanto os extratos e fases obtiveram uma classificação "ultra" nessa região. Nota-se que possivelmente a variação sazonal e temperatura provocaram mudanças de rotas biossintéticas no vegetal implicando numa diminuição dos metabólitos no período seco o que acarretou numa diminuição do FPS nesse mesmo período. Os valores do FPS encontram-se dispostos na Tabela 1.

Tabela 1 - Valores de FPS e razão UVA/UVB calculados para padrões e para cada extrato, fase e óleo essencial de galhos e folhas de Aniba canelilla.

\begin{tabular}{lcccc}
\hline \multirow{2}{*}{ Amostras } & \multicolumn{2}{c}{ Período Seco } & \multicolumn{2}{c}{ Período Chuvoso } \\
\cline { 2 - 5 } & FPS & Razão UVA/UVB & FPS & Razão UVA/UVB \\
\hline Extrato Bruto de Galhos & 27,70 & 1,06 & 34,83 & 0,87 \\
Extrato Bruto de Folhas & 42,80 & 2,82 & 90,25 & 1,64 \\
Fase Diclorometânica de Galhos & 122,60 & 1,12 & - & - \\
Fase Diclorometânica de Folhas & 116,52 & 1,54 & - & - \\
Fase Hexânica de Galhos & 54,23 & 3,92 & - & - \\
Fase Hexânica de Folhas & 37,21 & 4,19 & - & - \\
Fase Hidroalcoólica de Galhos & - & - & - & - \\
Fase Hidroalcoólica de Folhas & - & - & 41,43 & 1,04 \\
Óleo Essencial de Galhos & 5,49 & 0,44 & 6,93 & 0,33 \\
Óleo Essencial de Folhas & 7,54 & 0,60 & 14,08 & 0,62 \\
Quercetina & 261,23 & 5,79 & 261,23 & 5,79 \\
Benzofenona & 289,80 & 1,04 & 289,80 & 1,04 \\
Ácido $p$-Aminobenzóico & 852,69 & 0,13 & 852,69 & 0,13 \\
Metoxinamato de Octila & 852,05 & 0,37 & 852,05 & 0,37 \\
Protetor Comercial & 72,08 & 1,48 & 72,08 & 1,48 \\
\hline
\end{tabular}

De acordo com a legislação brasileira, RDC $N^{\circ} 30$ de $1^{\circ}$ de Junho de 2012 (Brasil, 2012), um produto para ser usado em cosméticos de fotoproteção, deve apresentar FPS no mínimo 6. Adiante disso, metabólitos de Aniba canelilla mostraram-se promissoras quanto sua utilização em formulações fotoprotetoras de acordo com o método examinado.

Conforme o estudo fitoquímico preliminar, a presença de flavonoides foi confirmada nos extratos das folhas e galhos de A. canelilla. Segundo Silverstein et al. (2005), os picos presentes no espectro da fase diclorometano dos galhos, fase com maior caráter fotoprotetor, representam transições que envolvem combinações de níveis vibracionais e rotacionais do estado fundamental e uma combinação correspondente no nível eletrônico excitado. Dessa maneira, quando a molécula absorve luz em seu comprimento de onda mais longo, um elétron é excitado do seu orbital ocupado de maior energia para o seu orbital vazio de menor energia. 
Assim, os extratos de A. canelilla podem apresentar compostos como flavonoides, cujas moléculas apresentam ligações conjugadas que possuem absorção máxima em comprimentos de onda maiores de $200 \mathrm{~nm}$, pois as flavonas e flavonóis oxigenados em seu anel-A apresentam uma alta intensidade na banda entre $240-285 \mathrm{~nm}$ e uma fraca intensidade na região $300-550 \mathrm{~nm}$, quando analisados no UV/Vis. Verifica-se, portanto, os espectros no UV desses flavonoides são análogos aos obtidos para a fase diclorometano dos galhos, tornando evidente a presença desses compostos nessa fase.

A Figura 2 exibe os espectros de absorção do extrato, das fases e dos óleos essenciais dos galhos e das folhas de $A$. canelilla.
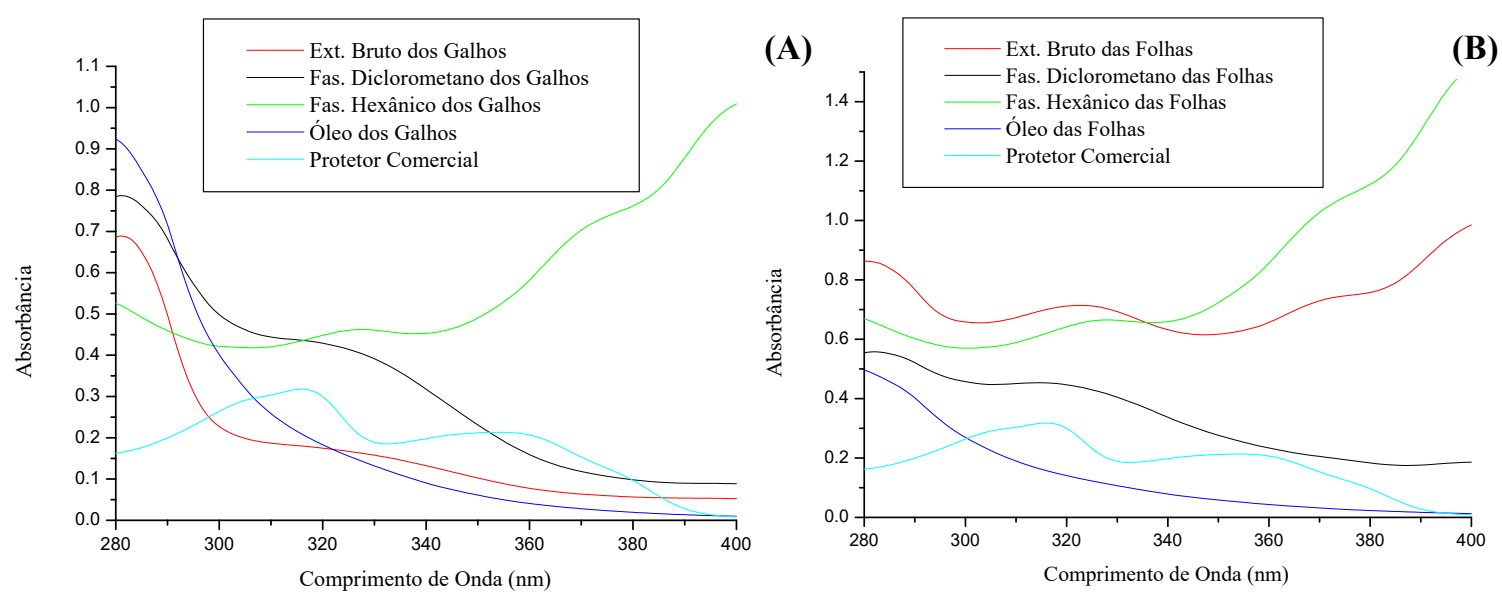

Figura 1 - Espectros de absorção do extrato, fases e óleos essenciais dos galhos (A) e das folhas (B) de Aniba canelilla coletados no período seco, e de um protetor solar comercial.

\section{CONCLUSÕES}

Os resultados obtidos demonstraram que, na concentração utilizada, a fase diclorometano dos galhos apresentou-se como a mais eficiente entre as demais amostras, quando comparada ao protetor solar comercial e a quercetina, filtro químico utilizado em protetores solares. Portanto, será realizado um estudo mais aprofundado em relação a sua composição química para que os constituintes responsáveis por essa atividade possam ser analisados e isolados. Visto que, de acordo com a legislação brasileira, RDC $\mathrm{N}^{\circ} 30$ de $1^{\circ}$ de Junho de 2012 (Brasil, 2012), um produto para ser utilizado em cosméticos fotoprotetores, deve apresentar FPS no mínimo 6. Dessa forma, extratos e fases de Aniba canelilla mostramse promissoras quanto sua utilização em formulações fotoprotetoras de acordo com o método avaliado.

\section{REFERÊNCIAS}

ARAÚJO, T. S.; SOUZA, S. O. Protetores solares e os efeitos da radiação ultravioleta. Scientia plena, v. 4, p. 5, 2008.

BOBIN, M. F.; RAYMOND, M.; MARTINI, M. C. UVA/UVB absorption properties of natural products. Cosmetics and toiletries, v. 109, n. 11, p. 63-70, 1994.

BOOTS THE CHEMISTS Ltd. (England). The Revised guidelines to the ractical 
measurement of UVA: UVB ratios according to the boots star rating system. Nottingham: The Boots CO PLC, 2004.

CHAAR, J. S. Estudos analíticos e modificação química por acetilação do linalol contido no óleo essencial da espécie Aniba Duckei Kostermans. Tese de Doutorado. Universidade de São Paulo.

INTERAMINENSE, L. F. L.; RAMOS-ALVES, F. E. S.; XAVIER, R. J. B.; DUARTE, F. E.; MAGALHÃES, G. P.; CALDAS, P. J.; MAIA, J. G. S.; SOUSA, P. J. C.; LAHLOU, S. Vasorelaxant effects of 1-nitro-2-phenylethane, the main constituent of the essential oil of Aniba canelilla, in superior mesenteric arteries from spontaneously hypertensive rats. European Journal of Pharmaceutical Sciences, v. 48, n. 4, p. 709-716, 2013.

MANSUR, J. S.; BREDER, M. V.R; MANSUR, M. C. A.; AZULEY, R. D. Determinação do fator de proteção solar por espectrofotometria. Anais Brasileiros de Dermatologia, v. 61, n. 3, p. 121-4, 1986.

MATOS, F. J. A. Introdução à fitoquímica experimental. Fortaleza: Editora UFC, 1997.

SANTANA, J. L.; PEÑA, M.; MARTINEZ, F.; GÓMEZ, A.; CORDONÍO, E.; GARCIA, O.; GARCIA, G.; VARGAS, L.M.; GARCIA, M.; GARCIA, C. Evaluación de la actividad antimicrobiana, fotoprotectora, antielastasa y antioxidante de polifenois de origen natural, empleados wen formulaciones cosméticas. XV Congresso Latinoamericano e Ibérico de Químicos Cosméticos. 2001.

SILVA, G. F. Estudo do Potencial biotecnológico de Aniba canelilla para obtenção de cosméticos. Dissertação de mestrado, Universidade do Estado do Amazonas, Manaus, 2012.

SILVERSTEIN, R. M; BASSLER, G. C.; MORRILL, T. C. Identificação dos compostos orgânicos. Rio de Janeiro: Editora Guanabara Koogan, 2005. 